\title{
PEMBERIAN KARTU FLASH TERHADAP KEMAMPUAN MEMBACA ANAK TK AZHARIYAH 12 ULU PALEMBANG
}

\author{
Asih Fatriansari \\ Prodi Ilmu Keperawatan STIK Siti Khadijah \\ Palembang Jalan Demang Lebar Daun Lorok Pakjo \\ Palembang 30117 \\ Email: asih.fatriansari@stik-sitikhadijah.ac.id
}

\begin{abstract}
Abstrak
Kemampuan anak dalam membaca merupakan salah satu tugas utama dalam tahapan perkembangan anak, khususnya pada tahap perkembangan bahasa dan kognitifnya. Kemampuan membaca pada usia dini (5 - 6 tahun) yang dimaksud adalah kemampuan untuk mengenal huruf. Pendekatan dalam rangka menstimulasi percepatan perkembangan kemampuan membaca anak sangat diperlukan, dikarenakan jika anak mengalami kesulitan atau keterlambatan pada perkembangan ini akan berakibat pada kesulitannya dalam mempelajari pelajaran pada tahap usia berikutnya (usia sekolah). Salah satu stimulus yang dapat digunakan adalah dengan menggunakan kartu flash. Tujuan dalam penelitian adalah untuk mengetahui efektiftas pemberian kartu flash terhadap kemampuan membaca anak di TK Azhariyah 12 Ulu Palembang. Penelitian ini menggunakan desain studi analisis kuantitatif dengan pendekatan preeksperimental. Sampel dalam penelitian ini adalah siswa TK Azhariyah 12 Ulu Palembang, dengan total sampling sebagai teknik yang diambil untuk penarikan sampelnya. Instrumen yang digunakan dalam penelitian ini adalah lembar observasi kemampuan membaca anak. Penelitian ini dilaksanakan tanggal 4 - 9 November 2019, dengan jumlah responden sebanyak 30 responden. Uji statistik yang digunakan dalam penelitian ini adalah uji paired sampel T-test. Hasil penelitian ini menunjukkan bahwa penggunaan kartu flash efektif dalam peningkatan kemampuan membaca anak di TK Azhariyah 12 Ulu Palembang ( $p=$ 0.000). Kartu flash sebagai media pembelajaran alternatif dalam rangka menstimulasi kemampuan membaca anak pada tingkat Taman Kanak-kanak.
\end{abstract}

\section{Kata kunci : kartu flash, kemampuan membaca anak}

\begin{abstract}
Children's reading ability is one of the main tasks in the stages of child development, especially at the stage of language and cognitive development. The ability to read at an early age (5- 6 years) is the ability to recognize letters. An approach in order to stimulate the accelerated development of children's reading skills is needed, because if the child experiences difficulties or delays in this development it will result in difficulty in learning lessons at the next stage of age (school age). One of the stimuli that can be used was flash card. The purpose of this study was to determine the effectiveness of providing flash cards on children's reading ability in Azhariyah's kindergarten 12 Ulu Palembang. This study used a quantitative analysis study design with a pre-experimental approach. The sample in this study were students of Azhariyah's kindergarten 12 Ulu Palembang, with total sampling as. The instrument used in this study was the children's reading ability observation sheet. This research was conducted on $4^{\text {th }}-9^{\text {th }}$ November 2019 , with a total of 30 respondents. The statistical test used in this study was the paired sample T-test. The results of this study indicate that the use of flash cards is effective in improving children's reading skills in Kindergarten Azhariyah 12 Ulu Palembang $(p=0.000)$. Flashcards as an alternative learning media in order to stimulate children's reading skills at the Kindergarten level.
\end{abstract}

Key words: flash cards, children's reading skills

Jurnal Kesehatan dan Pembangunan, Vol. 11, No. 21, Januari 2021 


\section{PENDAHULUAN}

Kemampuan membaca dan menulis merupakan pembelajaran yang dasar dan utama pada anak, sehingga memberikan stimulus-stimulus sejak usia dini sangatlah perlu. Beberapa sekolah tidak menggunakan tes masuk berupa kemampuan membaca dan berhitung, namun masih banyak Sekolah Dasar (SD) sering kali mengadakan serangkaian tes masuk untuk menyating calon siswa, salah satunya adalah tes kemampuan membaca. (Siantayani, 2011)

Untuk mengajarkan kemampuan membaca pada anak, perlu mengetahui tahapan perkembangan kemampuan membaca pada anak, menurut Aulia (2011) dalam Delrefi dkk (2017), perkembangan dasar kemampuan membaca pada anak usia $5-6$ tahun berlangsung dalam lima tahap yakni, tahap fantasi (magical stage1, tahap pembentukan konsep diri (self concept Stage1, tahap membaca gambar (bridging reading stage $j$, tahap pengenalan bacaan (take- off reader stage), tahap membaca lancar (independent reader stage).

Jika anak pada usia permulaan sekolah tidak segera memiliki kemampuan membaca, anak akan mengalami kesulitan dalam mempelajati bidang studi lain. Menurut Khoiriyah (2006) dalam Septiansyah (2017), beberapa orang tua mengaku bahwa mengajarkan membaca adalah sebuah tantangan berat bagi orang tua dan guru, karena anak cenderung susah untuk diajari membaca.

Untuk dapat mengajarkan membaca dengan baik maka diperlukan kesiapan membaca. Menurut Doman dalam Susanto (2014) dalam mengajarkan membaca harus dimulai dengan mengeja, pengenalan huruf kemudian mengenal kata, dan akhimya pengenalan kalimat, agar mencapai tujuan tersebut, pada tingkat Taman Kanak-kanak (TK) telah diberikan pengenalan membaca melalui pendekatan yang sesuai dengan tahap perkembangan anak, anak tidak diajarkan materi secara langsung, namun sesuai dengan prinsip bermain sambil belajar karena dengan permainan menjadikan salah satu cara terbaik untuk mengembangkan potensi anak didik. Metode bermain yang tepat menurut Siantayani (2011), akan menghilangkan kekhawatiran bahwa anak akan terbebani otaknya, mengalami kebosanan maupun membenci aktivitas belajar sehingga kemampuan membaca dapat meningkat, Salah satu metode untuk meningkatkan kemampuan membaca anak menurut Windura (2010) adalah dengan media flashcard. Flashcard atau kartu kilas adalah suatu kartu bolak balik yang sangat ampuh digunakan untuk niengingat dan kaji ulang proses belajar.

Beberapa penelitian terkait kartu flash sebagai salah satu metode dalam upaya meningkatkan kemampuan membaca anak telah mengungkapkan hasil yang menyatakan adanya keterikatan diantara keduanya, salah satunya hasil penelitian Anis (2016) yang menyatakan bahwa terdapat pengaruh media flashcard terhadap kemampuan membaca permulaan anak pada kelompok B TK Pertiwi Keprabon Polanhatjo Klaten Tahun Ajaran 2015/2016. Hasil penelitian terkait lainnya, diungkap dalam penelitian Nuri (2018) yang menunjukkan hasil bahwa media flashcard berpengaruh terhadap kemampuan membaca permulaan anak. Sedangkan hasil penelitian lainnya yang diungkapkan oleh Mochamad dan Putu (2018) tentang pengaruh media flashcard terhadap kemampuan kognitif di TPA Yayasan Pantisila Santo Rafael Singaraja yang menunjukkan bahwa terdapat pengaruh media flashcard terhadap kemampuan kognitif anak.

Pentingnya usaha stimulasi peningkatan kemampuan membaca sebagai salah satu bentuk dari tugas perkembangan kognitif anak, mendasari peneliti tertarik untuk melakukan penelitian yang berjudul efektifitas penggunaan kartu flash terhadap kemampuan membaca anak di TK Azhariyah 12 Ulu Palembang.

\section{METODE PENELITIAN}

\section{Jenis Penelitian}

Penelitian ini merupakan penelitian kuantitatif, dan desain yang digunakan dalam penelitian ini adalah Quasy Experiment 
dengan pendekatan one group pre-test and post-test.

\section{Waktu dan Tempat Penelitian}

Penelitian telah dilakukan pada tanggal 4-9 bulan November 2019 bertempat di TK Azhariyah 12 Ulu Palembang.

\section{Target/Subjek Penelitian}

Populasi subjek dalam penelitian ini adalah anak yang berumur $5-6$ tahun di TK Azhariyah 12 Ulu Palembang sebanyak 30 orang. Sedangkan enarikan sampel menggunakan metode total sampling (seluruh populasi), yaitu berjumlah 30 orang.

\section{Prosedur}

Prosedur penelitian ini dimulai setelah mendapatkan persetujuan baik dari tempat penelitian dan subjek penelitian. Kemudian peneliti melakukan observasi sebelum diberikan perlakuan dan sesudah diberikan perlakuan, kemampuan membaca diukur terlebih dahulu (pre test) sebelum diberikan kartu flash dan setelah diberikan kartu fiash kemampuan membaca diukur kembali (post test). Pengukuran kemampuan membaca dilakukan dengan cara mengobservasi checklis yang sudah valid dan reliabel.

\section{Data, Intrumen, dan Teknik Pengumpulan Data}

Sumber data dalam penelitian ini adalah data primer yang diperoleh dari subjek penelitian dengan menggunakan media berupa kartu flash, data tersebut berupa data pada isian lembar observasi terhadap kemampuan membaca anak di TK Azhariyah 12 Ulu Palembang.

\section{Teknik Analisis Data}

Metode analisa data pada penelitian ini terdiri dari analisis univariat dan bivarat. Analisa univariat dilakukan terhadap tiap variabel dari hasil penelitian yang hanya menghasilkan data numerik, yang disajikan berupa data mean/ median, standar deviasi dari setiap data yang dihasilkan. Sedangkan analisis bivariat digunakan untuk melihat apakah ada hubungan antar variabel. Dalam penelitian ini analisis yang digunakan adalah dengan menggunakan uji paired sampel t-test, dikarenakan data terdistirbusi secara normal. dengan ketentuan jika $\mathrm{p}$ value $<0,05$ maka dinyatakan ada pengaruh, dan sebaliknya jika $\mathrm{p}$ value $>0.05$ maka dinyatakan ada pengaruh.

\section{HASIL PENELITIAN dan PEMBAHASAN}

\section{Analisis Univariat}

Analisis ini digunakan terhadap variabel dalam penelitian untuk mengetahui skor kemampuan membaca anak sebelum dan sesudah diberi kartu flash dapat dilihat pada table 1 dan 2 .

Tabel 1. Skor kemampuan membaca anak sebelum diberi kartu flash

\begin{tabular}{|c|c|c|c|c|c|}
\hline $\begin{array}{l}\text { Variabel } \\
\text { penelitian }\end{array}$ & Mean & Median & $\begin{array}{l}\text { Std. } \\
\text { Dev }\end{array}$ & $\begin{array}{l}\text { Min- } \\
\text { Max }\end{array}$ & $95 \% \mathrm{CI}$ \\
\hline $\begin{array}{l}\text { Skor } \\
\text { kemampuan } \\
\text { membaca } \\
\text { sebelum } \\
\text { Perlakuan }\end{array}$ & 11.20 & 11 & 2.280 & $\begin{array}{l}7- \\
15\end{array}$ & $\begin{array}{l}10.35- \\
12.05\end{array}$ \\
\hline
\end{tabular}

Tabel 1 menjelaskan bahwa sebelum diberikan perlakuan didapatkan rata-rata skor kemampuan membaca anak sebelum diberi kartu flash adalah 11.20 dengan standar deviasi 2.280, dan nilai CI 95\% adalah 10.35 - 12.05, serta skor terendah adalah 7 sedangkan skor tertinggi adalah 15 .

Tabel 2 skor sesudah

\begin{tabular}{lccccc}
\hline $\begin{array}{l}\text { Variable } \\
\text { penelitian }\end{array}$ & Mean & $\begin{array}{c}\text { Medi } \\
\text { an }\end{array}$ & $\begin{array}{c}\text { Std. } \\
\text { Dev }\end{array}$ & $\begin{array}{c}\text { Min- } \\
\text { Max }\end{array}$ & $\begin{array}{c}\text { 95\% } \\
\text { CI }\end{array}$ \\
\hline $\begin{array}{l}\text { Skor } \\
\text { kemampuan } \\
\text { membaca }\end{array}$ & 15.40 & 15 & 2.593 & - & - \\
$\begin{array}{l}\text { setelah } \\
\text { Perlakuan }\end{array}$ & & & & 18 & 16.00 \\
\hline
\end{tabular}

Tabel 2 Menjelaskan bahwa rerata skor kemampuan membaca anak setelah diberi kartu flash adalah 15.40 dengan standar deviasi 2.593 dan nilai CI 95\% adalah 14.80 
- 16.00 serta skor terendah adalah 12 sedangkan skor tertinggi adalah 18.

\section{Analisa Bivariat}

Efektifitas Pemberian Kartu Flash terhadap Kemampuan Membaca Anak dapat dilihat pada table 3 .

Table 3. Efektifitas Pemberian Kartu Flash terhadap Kemampuan Membaca Anak

\begin{tabular}{lcccc}
\hline $\begin{array}{l}\text { Variabel } \\
\text { penelitian }\end{array}$ & Mean & Std. Dev & 95\%CI & P-value \\
\hline $\begin{array}{l}\text { Skor kemampuan } \\
\text { membaca setelah }\end{array}$ & 11.20 & 2.280 & $10.35-12.05$ & 0.000 \\
$\begin{array}{l}\text { Perlakuan } \\
\begin{array}{l}\text { Skor kemampuan } \\
\text { membaca setelah } \\
\text { Perlakuan }\end{array}\end{array}$ & 15.40 & 2.593 & $14.80-16.00$ & \\
\hline
\end{tabular}

Hasil dalam penelitian ini didapatkan $\mathrm{p}$ value 0.000 (nilai $\mathrm{t}$ hitung < dari t tabel yaitu $-8.931<-2.032$ ), dapat disimpulkan ada pengaruh yang signifikan antara kemampuan membaca sebelum dan sesudah diberi kartu flash di TK Azhariyah 12 Ulu Palembang tahun 2019. Hasil ini sejalan dengan teori Arsyad (2017), yang menyatakan bahwa flashcard atau kartu abjad dapat digunakan untuk mengeja lancar dan melatih siswa mengeja dan memperkaya kosakata serta dapat menjadi petunjuk dan rangsangan bagi siswa untuk memberikan respon yang diinginkan.

Sedangkan menurut Riyana dan Susilah (2009), berbeda sedikit intrumen yang diberikan, yaitu dengan menggunakan flashcard yang berukuran kecil (dapat disimpan di tas bahkan di saku). Flashcard tersebut menyajikan pesan-pesan pendek pada setiap kartu yang disajikan. Namun ternyata hasilnya, dengan pesan-pesan pendek tersebut siswa lebih mudah untuk mengingatnya.

Teori lain yang mendukung hasil penelitian ini adalah definisi kemampuan membaca oleh Wulan, dkk (2014), yang menyatakan bahwa kemampuan membaca termasuk kegiatan yang kompleks dan melibatkan berbagai keterampilan. Jadi, kegiatan membaca merupakan kegiatan terpadu yang mencakup beberapa kegiatan, seperti mengenali huruf dan kata-kata, menghubungkan dengan bunyi, maknanya serta kesimpulan mengenai maksud bacaan. Pendapat lain terkait kemampuan membaca diungkap oleh Anderson, dkk (1985) dalam Wulan, dkk (2014), yang menyatakan bahwa membaca sebagai suatu proses untuk memahami makna suatu tulisan. Proses yang dialami dalam membaca adalah berupa penyajian kembali dan penafsiran suatu kegiatan dimulai mengenal huruf, kata, ungkapan, frase, kalimat dan wacana serta menghubungjan dengan dan maknanya, bahkan lebih jauh dari itu dalam kegiatan membaca, pembaca menghubungkannya dengan maksud penulis berdasarkan pengalamannya.

Kegiatan membaca menurut Wulan, dkk (2014) terkait oleh beberapa hal sebagai berikut:

1. Pengenalan huruf atau aksara

2. Bunyi dari huruf atau rangkaian hurufhuruf

3. Makna atau maksud

4. Pemahaman terhadap makna atau maksud berdasarkan konteks wacana

Terdapatnya efektifitas pemberian kartu flash terhadap kemampuan membaca anak, ini juga sesuai dengan adanya teori terkait dengan kemampuan-kemampuan kesiapan membaca menurut Wulan, dkk (2014). Kemampuan-kemampuan kesiapan membaca anak yang dapat mendukung hasil penelitian ini adalah kemampuan membedakan auditorial, kemampuan diskriminasi visual, dan kemampuan perseptual motoris, dan kemampuan bahasa lisan.

Selain faktor kesiapan membaca anak, kemampuan membaca anak juga dipengaruhi oleh faktor-faktor lainnya yang diungkap oleh Tampubolon (1990) dalam Wulan, dkk (2014). Namun menurut analisis peneliti, faktor yang mempunyai keterikatan dengan hasil penelitian ini adalah faktor bahan bacaan. Bahan bacaan dalam hal ini adalah kartu flash yang diberikan kepada anak. karena kartu flash yang diberikan mempunyai karakteristik yang anak-anak sukai, berupa pengenalan huruf dengan 
menampilkan gambar-gambar binatang dalam bentuk gambar kartun.

Selain ditunjang oleh teori-teori pendukung di atas, hasil penelitian ini juga didukung adanya hasil penelitian terkait yang sejalan. Salah satunya adalah penelitian oleh Nuri (2018) di TK Pertiwi 01 Girilayu, yang menyatakan hasil penelitiannya bahwa terdapat pengaruh flashcard dengan kemampuan membaca permulaan anak dengan hasil $\mathrm{t}$ hitung < dari t tabel yaitu $23.453<-2.093$. Penelitian lain yang terkait, adalah penelitian oleh Mochamad dan Putu (2018) di TPA Yayasan Pantisila Santo Rafael Singaraja, yang mendapatkan hasil bahwa didapatkan adanya pengaruh media flashcard terhadap kemampuan kognitif anak dengan $\mathrm{p}$ value $=0.000(<0.05)$.

Dari hasil penelitian, teori, dan penelitian terkait, dapat disimpulkan bahwa kartu flash cukup efektif dalam meningkatkan kemampuan membaca anak, karena karakteristik kartu flash menyajikan pesan-pesan pendek pada setiap kartu yang membuat pembelajaran gampang diingat.

\section{KESIMPULAN}

Berdasarkan hasil penelitian ini, dapat disimpulkan bahwa:

1. Rerata skor kemampuan membaca anak sebelum diberi kartu flash adalah 11.20 dengan standar deviasi 2.280, dan nilai CI $95 \%$ adalah 10.35 - 12.05 , serta skor terendah adalah 7 sedangkan skor tertinggi adalah 15 .

2. Rerata skor kemampuan membaca anak setelah diberi kartu flash adalah 15.40 dengan standar deviasi 2.593 dan nilai CI 95\% adalah $14.80-16.00$ serta skor terendah adalah 12 sedangkan skor tertinggi adalah 18 .

3. Dari hasil uji Paired T-test didapat nilai p: $\quad 0.000$ yang berarti bahwa pemberian kartu flash efektif terhadap peningkatan kemampuan membaca anak.

\section{SARAN}

Saran yang dapat peneliti berikan adalah sebagai berikut:

1. Menjadikan kartu flash sebagai media belajar alternatif dalam rangka stimulasi peningkatan kemampuan membaca anak pada anak di tingkat Taman Kanak-kanak (TK).

2. Diperlukan penelitian lanjutan dengan menggunakan metode Kohort atau case control untuk melihat faktor-faktor yang paling berperan dalam mempengaruhi kemampuan membaca anak.

\section{UCAPAN TERIMA KASIH}

Penulis mengucapkan terima kasih kepada semua pihak yang telah memberi dukungan terhadap pelaksanaan penelitian ini.

\section{DAFTAR PUSTAKA}

Anis Fadillah Nindyawati. 2016. Media Flashcard Berpengaruh Terhadap Kemampuan Membaca PerrriulaanAnak. Jumal. Surakarta : Universitas Muhammadiyah Surakarta.

Arsyad, Azhar. 2017. Media Pembelajaran. Jakarta : PT Raja Grafindo. Jakarta Persada.

Delrefi ,D, Sumarsih \& Dwi Nainggolan. 2017. Pengaruh Metode Fernald Terhadap Kemampuan Membaca Permulaan Pada Anak Kelompok A Di Paud Mekar Sari Penarik Muko-Muko. (Jumal, Vol. 2, No.I: 2017) Penarik MukoMuko : FKIP UNIB.

Mochamad Heri dan PutuAgus Ariana. 2018. Pengaruh Media Flashcard Terhadap Kemampuan Kognitif Anak Di TPA Yayasan Pantisila Paud Santo Rafael Singaraja. (Jumal. Vol 3, No. 2: 2018). 
Nuri Farida Astuti. 2018. Pengaruh Media Flashcard Terhadap Kemampuan Membaca Permulaan Anak Kelompok B TK Pertiwi 01 Girilayu. Jurnal. Surakarta: Universitas Muhammadiyah Surakarta. 
Jurnal Kesehatan dan Pembangunan, Vol. 11, No. 21, Januari 2021 